\title{
THE EFFECTIVENESS OF ENVIRONMENTAL PERFORMANCE MEASURES IN ENSURING SUSTAINABLE DEVELOPMENT: THE WATER AND AGRICULTURAL INDUSTRIES HIGHLIGHTED
}

\author{
$\underline{\text { A R Johnston and K A Lewis }}$ \\ Division of Environmental Sciences, University of Hertfordshire
}

\begin{abstract}
$\underline{\text { Abstract }}$
If businesses are to contribute to green sustainable development, then a method of measuring progress is essential. Accounting methods need to be used that indicate to the organisation and the general public the businesses progress towards sustainability. Sustainability, by some definitions, refers to the degradation or depletion of natural resources i.e. the direct and indirect environmental effects. For example, consider the effect of pesticides contaminating water. Sustainability would reflect the degradation of the water quality and the disturbance of the waters aquatic eco-system, the damage to aquatic life and the possible human and animal health effects. Consequently, by this definition, sustainability is equivalent to the environmental effects

This paper discusses what considerations are required in order to identify environmental performance measures (EPM's) which reflect the progress towards sustainable development and which measure environmental performance.

EPM's can be used in a wide variety of ways and this is illustrated with respect to two research projects currently being carried out at the University of Hertfordshire. The first, discusses the use of corporate EPM's with the water industry of England and Wales by examining company environmental reports. The second, uses EPM's to measure environmental performance and the goal of both business and green sustainability within arable agriculture.
\end{abstract}

\section{$\underline{\text { Introduction }}$}

Environmental issues remain at the top of the political agenda. Rarely a week goes by without the media reporting some pressure group somewhere protesting about one particular development or another. It may seem to many people that a growing number of individuals see all development, industrial, leisure or otherwise, as detrimental to the environment. Development, however, is essential if we are to maintain income and lifestyle both on an individual and a global scale. Consequently, sustainable development is the only way of satisfying the needs and demands of all. In the case of non-renewable resources, any use whatsoever is depletion and non-sustainable but in many cases a suitable alternative renewable resource is not available and so the viability of the business is dependant on the depletion of the resource. The only answer, until technology allows otherwise, is to minimise the use of non-renewable resources.

This paper discusses sustainable development issues and the possibilities of using EPM's to track progress towards sustainability as well as reflecting environmental impact. The possibility of using such measures and their effectiveness with respect to the both the water and agricultural industries in England and Wales is discussed. The water industry study uses company reports to evaluate the industries use of these measures. The second project is utilising EPM's to quantify environmental impact and sustainability of arable agricultural enterprises.

\footnotetext{
${ }^{1}$ Sustainable Development, Vol 3:3 Dec 1995,pp 140-148
} 


\section{Sustainable Development}

Sustainable development has been defined (WCED, 1993) as "development that meets the needs of the present without compromising the ability of future generations to meet their own needs". This can be interpreted as the level of income an organisation can afford to pay without depleting its capital stocks, be they man-made or natural. Here, the term organisation includes governments, major industries and small businesses, all who must protect their resources for the sake of share holders and/or their customers.

From the original definition of sustainable development the following equation, is widely quoted and commonly referred to as the "Weak Sustainability Model" (Pearce, 1993).

$$
\text { gNNP }=(C+S)-\text { Detr.KM - Dep.KN - Deg.KN }
$$

Where:

$$
\begin{aligned}
\text { gNNP } & =\text { 'Green' Net National Product or Income } \\
\mathrm{C} & =\text { Consumption } \\
\mathrm{S} & =\text { Savings }
\end{aligned}
$$

Detr.KM = Deterioration of man made capital.

Dep.KN $=$ Depletion of natural capital

Deg.KN = Degradation of natural capital

Examining equation 1 more closely, a resource is depleted if there is less available at the end of the accounting period than there was at the beginning. For a renewable resource this means that the rate of utilisation exceeds the rate of production or growth. For a non-renewable resource, any utilisation results in its depletion and to ensure sustained development a renewable alternative should be found. The major weakness of this model, and hence its common name, is that the gNNP is directly related to the sum of both renewable and non-renewable resources. So if the stock of renewable resources is increased but the stock of non-renewable resources is depleted then gNNP may remain steady or actually improve in these circumstances. In many cases non-renewable resources have no suitable, renewable alternative and the viability of the business itself is therefore dependant on the depletion of that natural resource.

A resource is degraded if its quality deteriorates over the accounting period. In financial terms, the cost would be the money spent returning the asset to its qualitative state at the beginning of the accounting period, assuming that this is possible. A second equation describes sustainable development from the environmental viewpoint (Bartelmus, 1994):

$$
\begin{aligned}
& \text { ENI = NNP - Environmental Welfare Costs } \\
& \text { ENI = Environmentally adjusted national income } \\
& \text { NNP = Net National Product. }
\end{aligned}
$$

.. Equ. 2 Where:

Equations 1 and 2 both combine conventional economic measures with environmental measures to explain green national income. 'Green' sustainable development is achieved when green national income does not decline over an accounting period.

Environmental economists have examined sustainability of the biosphere using a variety of environmental performance measures (EPM's) with respect to pollutant media such as water and air. However, EPM's relate to human activities such as the generation of waste or the use of resources in manufacturing and so will work best if differentiated by region or organisation. Businesses control a dominant proportion of world economic activity, thereby influencing technology, political power, land use, employment, human choice and, ultimately, the environment (Gray et al, 1993).

\section{$\underline{\text { Environmental Performance Measures }}$}


A method of 'green' accounting should be equally applicable to businesses both large and small. Reinterpretation of equation 1 to make it applicable at the corporate level could be:

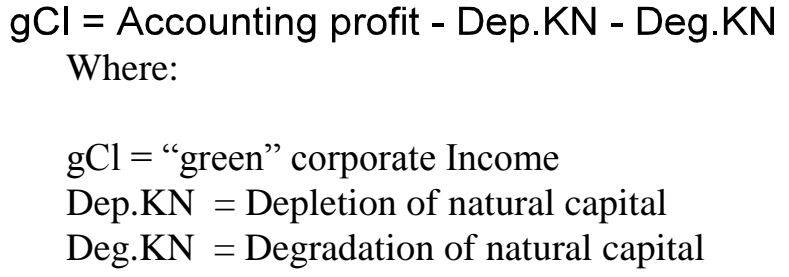

Measurement of a business' environmental performance can be achieved by selecting a set of factors which combine to satisfy the environmental concerns of company stakeholders and the requirements of the environment itself. If these factors are quantifiable, progress towards improved environmental performance and green sustainability is measured. There are obvious links here with the British Standard in Environmental Management (BS7750) where identification of the performance factors is comparable with identification and ranking of significant environmental effects. If monitoring and measurement of these effects is not achieved then progress towards agreed objectives and targets cannot be measured.

Recent research (James and Bennett, 1994) has investigated several different types of EPM's and why organisations are beginning to use them. Generally, there are several reasons why such measures are being utilised. The most important being the:

- recognition of the importance of sustainable development and

- demand by financial stakeholders, customers, pressure groups, regulatory bodies and the general community for reassurance that environmental damage is minimised.

The same reasons have caused a marked increase in the number of companies using environmental management systems such as BS7750.

An effective EPM has to satisfy two main criteria. Firstly, it must record the depletion and degradation of resources. This may be achieved, for example, using purchasing and waste disposal records or by examining the ratio of material inputs and waste outputs or waste output per unit product as measures of wastage efficiency.

Secondly, it should have be a scalar quantity. The use of nominal measures where, for example, a factor is simply true or false does not allow either sustainability or environmental impact to be quantified. Generally accepted measures include:

- comparison with standards or agreed limits,

use of a measurement unit such as inches or $\mathrm{mg} / \mathrm{l}$,

- use of an accounting period i.e. the differential between levels at the start and end of the period, although this does not explicitly measure environmental impact.

The criteria, therefore, for a successful EPM, such that both the progress towards sustainable development and environmental performance is measured, is that the measures selected must reflect the environmental and other business concerns, be related to significant environmental effects and be quantifiable on a recognised and accepted scale.

The University of Hertfordshire is currently carrying out two research projects involving EPM's within two different industrial sectors: the water industry and the agricultural industry. The water industry study looks at company reports to gain information on the way the industry is using EPM's, how these have developed over time, the influence of regulators and how successful the processes have been. The agricultural industry however is very different. Generally, the business enterprise is much smaller and, unlike the water industry, it is not as heavily regulated, although this is changing rapidly. Most of the current environmental pressures come from the supply chain. Consequently, the business reporting procedures are less highly developed and environmental reports are virtually unheard of. There is currently, however, a considerable amount of research seeking to develop a more structured and methodical approach to environmental management in agriculture. One such project is discussed below. 


\section{Using Environmental Performance Measures in the Water Industry}

\section{Background}

Before the 1989 Water Act came into force there were ten regional water authorities supplying water and sewerage services and 29 statutory companies supplying water only. The 1989 Act allowed the water and sewage functions of the old authorities to be transferred to ten new private sector companies (water services plc). After mergers and takeovers, there are now 21 'water only companies'.

The water industry provides a useful case study, since as well as financial reports, every 'water only company' produces comprehensive environmental reports on 'Conservation Access and Recreation' and, in addition to these requirements, the water service plc's (supply and sewerage) publish voluntary 'Environmental Reports'. Consequently, the water industry of England and Wales provides an example of a privately owned industry which has attempted to measure its environmental performance.

\section{Methodology}

The effectiveness of corporate EPM's in delivering sustainable development was assessed by examining the EPM's employed in company environmental reports and identifying whether they 'inform degradation or depletion of natural stock'. An EPM was said to 'inform degradation or depletion' if the application of a weighting system or scientific knowledge to the measure allows the company to quantify, however crudely, the impact on the environment. For example, the total discharge per day from a sewage treatment works together with information on the chemical composition of the discharges would give a quantifiable measure of degradation and so can be said to 'inform degradation or depletion of natural stock'. However, an EPM relating to the number of treatment works failing discharge consents can not lead to quantifiable data on degradation or depletion because it would not be known what caused the failures.

At present much of the debate surrounding EPM's and environmental management has focused on voluntary initiatives but regulation has increased significantly over recent years and so note was made of whether an EPM was driven by regulatory means. Sets of accounts from 1989/90 to 1994 were examined to assess progress in environmental reporting. A larger sample of reports from 1994 helped to confirm findings and allowed for a more in depth study of the present situation. As well as investigating EPM's, evidence of financial allowances for degradation and depletion in the accounts was sought.

Accounts

Full sets of accounts from 1989/90 to 1994 were examined for four water service plc's and four 'water only companies', to identify trends and changes in reporting since the 1989 Water Act. Previous financial reports, as opposed to environmental reports, were examined because of their availability and consistency over the time period. Where these reports and accounts were prepared for the company group rather than the regulated water company, efforts were made to focus on the latter. Note was made of the number of environmental subjects mentioned, the quality of the information and whether the measure informed degradation or depletion of natural stocks. When the managing director's report and the chairman's statement duplicated information this was only counted once.

Preliminary examinations identified five broad categories of statement ranging from those considered vague to those which included fully quantified data. Therefore it was possible to develop a simple ranking system. The quality of information provided was assessed by assigning an ordinal scale to the identified environmental statements as given below. The data were then assimilated to give a final rating or 'measure quality rating'.

$$
\begin{array}{r}
\text { Vague statement }-1 \text { point } \\
\text { Detailed statement }-2 \text { points } \\
1 \text { or } 2 \text { point statement with a named source }-3 \text { points } \\
\text { Partially quantified data }-4 \text { points } \\
\text { Fully quantified data }-5 \text { points }
\end{array}
$$


In addition, the 1994 accounts were examined for a further 4 water service plc's and two water companies giving a total of 14 sets of accounts. These reports were examined for the same features as those from 1989 to 1994 and were used as a check on the accuracy of the sample results and an illustration of the present situation. Note was made of any regulatory influences in these reports. All sets of accounting tables were examined for evidence of financial reporting of EPM's which informed degradation and depletion.

\section{Environmental reports}

Environmental reports from eight water service plc's were examined to identify the types of measures used and their contribution to corporate sustainable development. Unlike financial reports, environmental reports are well stocked with prose extolling the virtues of the company. These could be interpreted as EPM's, for example, the presence or absence of an environmental management system is considered, by some, as an EPM. To have attempted to assimilate these data would have been too unwieldy and consequently only quantified measures were examined. Each report was examined and the measures used were sub-divided by subject area as defined in the Northumbrian Water Report (which had the most comprehensive scope of subjects). The number of times an EPM was used, the influence of the regulators, and whether or not degradation and depletion were informed by the EPM were all recorded.

\section{Financial reports and accounts over the last five years.}

The data from financial reports and accounts for 'water only companies' from 1989/90 to 1994 are given in Table 1. This shows that the number of EPM's and those informing degradation and depletion declined from 1990 to 1992 but rose again to 1994 to show an increase in the five years. This could be attributed to a declining importance in drought issues from 1990 to 1992 and then other environmental issues gaining prominence over recent years. The average score per 'measure quality rating' showed a steady rise until 1993 but declined in 1994, the high of 2.97 is still below the rating of 4 which indicates some quantification of the EPM's.

Data from financial reports and accounts for water services plc's from 1989/90 to 1994 are given in Table 2. These data illustrate that the average number of EPM's used and their quality rating increased over the five years, but those measures informing degradation and depletion have actually declined.

There is little difference between the numbers of measures informing degradation and depletion for 'water only companies' but for water service plcs there are more degradation measures than depletion which reflects the sewage function of these companies. In both sectors the number of EPM's informing degradation and depletion formed roughly half the total EPM's. No financial allowance for natural stocks was made in any of the accounting tables examined.

\section{Financial reports and accounts for 1995.}

Data from water industry financial reports for 1994 are shown in Table 3. The water service plc's reported on more EPM's than the 'water only companies', confirming the findings in Tables $1 \& 2$. Water service companies reported on more degradation measures than 'water only companies' but the number of depletion measures remained similar. For both sectors of the industry, when degradation was measured, in all cases the information was originally required by an industry regulator. The lower percentages for regulatory influence on depletion measures could be explained by measuring energy consumption and waste management. The quality rating per measure shows that in both sectors an average EPM is not quantified.

The water service plc's appear to have been more affected than the 'water only companies', by the increase in environmental awareness since 1989. They report more measures with steadily improving quality. However, the number of EPM's which inform degradation and depletion has decreased over the five year period and increased in the 'water only companies'. This could be due to the realisation of the risk involved in reporting environmental impacts which are possible future liabilities. Alternatively, the decline could be explained by a policy of concentrating on process measures 
because they are easier to measure and manage. A third possibility is that water service plc's have more degradation issues to deal with and which are harder than depletion issues to quantify.

\section{Environmental reports}

Data for the number of EPM's per subject area and those driven by regulators in environmental reports for the water service plc's are given in Table 4. The data show that there are three main subject areas for EPM's in water service plc's environmental reports. These are: inland surface and ground water quality, water resources and conservation. Those subject areas with few or no EPM's include sustainability, supplier performance and environmental management. These findings indicate that EPM's in core functions of the companies are well developed but wider environmental issues are not. The number of measures informing depletion and degradation are about the same (12 and 13 respectively) and combined these measures account for 30\% of the total number of EPM's.

Regulatory influences account for 12 out of 13 degradation measures and 5 out of 12 depletion measures. Combined this amounts to 68\%. Regulator pressure was evident in $69 \%$ of the measures and appears to have the same effect on degradation and depletion informing EPM's and the total number of EPM's. This indicates that the regulators are setting the agenda for EPM development in the water industry, which is very heavily regulated. This is especially true of degradation EPM's where a regulator's request provides a 'level playing field' in which to report.

In conclusion, the EPM's discussed have limited effectiveness in delivering corporate sustainable development. No EPM was found that actually quantitatively measured a single impact on the environment and no evidence of accounting for degradation or depletion of natural stocks was found in the accounting tables examined. Much progress has been made especially by the water industry which is a leader in this field but sustainable development provides an elusive and challenging target. As Welford (1993) pointed out current environmental management practice is not bad, the problem is that re-thinking business strategy along the lines of sustainable development requires a change in corporate culture. In other words companies wishing to be seen to have environmental issues high on their agendas will need to concentrate more on quantifying environmental impacts more generally and measures of sustainability in particular.

\section{Using Environmental Performance Measures in Arable Agriculture}

\section{Background}

In arable agriculture the most important resource to the farmer is his soil and with respect to business viability crop yields are his profit. However, normal farming practices can have quite significant impacts on the environment, for example through the use of fertilisers and pesticides. Currently, farming is as heavily regulated as the water or manufacturing industries, although this is rapidly changing. The main environmental pressures on farming come from the National Rivers Authority which is mainly concerned with preventing water pollution and secondly from the supply chain which is mostly concerned with the use of pesticides and fertilisers and their effects upon the food chain and water quality.

Without the use of man-made fertilisers, however, crop yields would be dramatically reduced due to the depletion of the soils nutrients. Without the use of pesticides, vegetation may be damaged resulting in reduced yields and/or damaged unsaleable produce. A balance between protecting both the environment and the business viability is required. This highlights the objectives of Agenda 21 which recognises the problems associated with providing food for an increasing global population from a land resource which is showing a gradual decline in its ability to grow crops (UN Environment and Development-UK, 1994).

At present, environmental performance measures are not widely used by the agricultural industry. However, pressures from the supply chain are filtering through and many farmers, if they wish to sell their produce to supermarkets or to the large grain millers, need to convince their customers that they are minimising environmental impact. Many of the major supermarket chains have a stringent Code of Practice for the use of fertilisers and pesticides. 
The Ministry of Agriculture, Fisheries and Food (MAFF) has published Codes of Practice for the Protection of the Environment (MAFF, 1991, 1992, 1993) and recommendations for the use of fertiliser (MAFF, 1994). There are also various other publications aimed at providing guidelines for the use of pesticides (HMSO, 1990), sewage sludge (HMSO, 1993). However, a positive response by the agricultural industry to these publications has not been widespread.

The University of Hertfordshire has now completed the first phase of a project aimed at promoting good environmental practice by agriculture within a profitable business framework using environmental performance measures. The first part of a computer-based package for the assessment of environmental performance and impact of arable agriculture is now operational.

\section{Methodology}

Analysis of significant environmental effects associated with arable farming led to the identification of quantifiable factors which could be used to assess environmental impact and progress towards sustainable development. Three main effects were identified:

- Water pollution due to the use of inorganic fertilisers.

Detrimental effects from the use of pesticides and

- Soil Degradation.

\section{Water pollution due to the use of inorganic fertilisers.}

The use of organic fertilisers significantly contributes to nitrate pollution and the contamination of drinking water supplies. The use of fertilisers also contributes to excessive concentrations of phosphate in surface waters within the UK resulting in eutrophication.

Recommendations for the quantities and application timing of nitrogen, phosphate and potash fertilisers required by specific crops, considering the soil type, its current nutrient level, and any organic manures already added, have been used as standards. These recommendations are based on typical yields and aim to give the best financial return based upon current prices of fertilisers and produce. The correct timing of fertiliser applications is important to ensure that crops fully utilise the nutrient supply such that an excess is not available and vulnerable to loss via water or air. For example, winter cereal crops use very little nitrogen during the cold months and so no benefit would be gained from applying fertiliser in the autumn. These recommendations aim to achieve the economic optimum yields, ensuring progress towards sustainability and ensuring environmental impact is minimised.

The relative error between actual quantities applied and the recommendations have been used to assess efficient fertiliser usage. Other factors such as the use of organic manures and or the soil analysis are also taken into account. Comparison of actual application timings with those recommended, together with an expert system approach and a simple ranking system have been used to estimate environmental risks from nutrient losses. This can be illustrated through a simple example:

A malting variety of Spring Barley was grown on a sandy soil having typical nutrient levels. An average application of farmyard manure had been previously made and $150 \mathrm{Kg} / \mathrm{ha}$ of nitrogen fertiliser was added.

Standard recommendations under these conditions are $100 \mathrm{Kg} / \mathrm{ha}$ total nitrogen. However approximately $5 \mathrm{Kg} / \mathrm{ha}$ had been supplied via the farmyard manure, therefore $95 \mathrm{~kg} / \mathrm{ha}$ should be added as fertiliser.

The assessment procedure considers that $+/-10 \%$ error on the recommendations is reasonable and acceptable. Beyond these levels the relative error is calculated from:

$$
\begin{aligned}
& \mathrm{E}=(\mathrm{R}-\mathrm{A}) * 100 / \mathrm{R} \\
& \text { Where: } \\
& \mathrm{E}=\text { error, representing the perceived environmental impact. } \\
& \text { nb. This error value is constrained to lie within the range }+100 \text { to }-100 \text {, } \\
& \text { with } 0 \text { representing the 'ideal'. } \\
& \mathrm{R}=\text { Recommended quantity of fertiliser as } \mathrm{Kg} / \mathrm{ha} .
\end{aligned}
$$


$\mathrm{A}=$ Actual quantity of fertiliser applied in $\mathrm{Kg} / \mathrm{ha}$.

Using the example above, equation 4 gives an error of $-58 \%$ reflecting the excessive nitrogen added. This also measures the risk to the environment from nitrate leaching and reduces profits through unnecessary fertiliser costs. Therefore this EPM meets the previously specified criteria. This does not reflect the possible soil degradation that may occur if less man-made fertiliser was added than required and nutrient levels were depleted. However, this issue is examined within the soil degradation assessment.

\section{Detrimental effects from the use of pesticides.}

Careless use of pesticides may result in contamination of watercourses, may have detrimental effects on aquatic life, cause unacceptable damage to species other than the target and result in human health problems.

The environmental impact of pesticides can be assessed via two factors.

The first factor is a measure of the spray's perceived toxicity. A number of different parameters contribute towards this factor. They may include:

Some measure of the pesticides toxicity and that of any adjuvant added to the spray solution. i.e. $\mathrm{LC}_{50}$ values.

- The final concentration of the pesticide, its rate and its frequency of application.

- A measure of the pesticide's environmental persistence, its pest selectivity and its rate of degradation.

The second factor is a measure of the farmer's need to spray. This can be assessed using one of two approaches depending upon the nature of the threat i.e. pest or disease. If it is a pest, then the "pest threshold value' is used. The number of pests per plant area is estimated and compared with the threshold value above which damage is considered unacceptable and spraying is required to protect yields. If the threat is a disease then a risk assessment approach is used and spraying should only be carried out when certain risk criteria are satisfied.

Assessment of the environmental impact of pesticide use is achieved using a combination of its perceived toxicity and the farmers need to spray. The impact is reported on an scale of +100 to -100 , a positive rating being awarded for minimal spraying and the use of a low toxicity pesticide. A negative rating being given for frequently, unnecessary spraying using a pesticide of high toxicity. Work in this area is still ongoing and detailed discussions relating to this are beyond the scope of this paper. This will be reported at a later date.

\section{Soil degradation.}

This may be described as the loss of soil quantity, soil quality or soil nutrients and may be the result of erosion, contamination, flooding, structural damage or improper management techniques. An expert system approach to assess compliance with good practice has been used here. User-supplied information regarding actual farming practices is compared with rules extracted from the Code of Good Agricultural Practice for the Protection of Soil (MAFF, 1993). Scores for compliance are totalled over all rules and compared with the total score perceived to represent the ideal. Typical examples of rules used in the assessment are given below:

Rule 1:

If sewage sludge is applied to agricultural land and if the soil's $\mathrm{pH}$ is below 5 then

'soil is acidic and the metals present in the sludge will become more available to plants and any adverse effects may increase.'

A negative environmental impact is seen.

Rule 2: 
If sewage sludge has been applied to agricultural land and if the crops grown on that land can be eaten raw then if the crop is harvested within 10 months of the sludge application

'non-compliance with regulations controlling the application of sewage sludge has occurred'. The regulations state that crops must not be harvested within 10 months and so a negative impact on the environment is recorded.

These EPM's have been incorporated into a software package aimed at assessing both environmental performance and environmental impact. The quantified EPM's are reported to the user together with qualification notes giving information on how environmental impact can be further minimised.

The research project described here is successfully using EPM's to quantify environmental performance. Although progress towards sustainable development is not actually reported by the software system explicitly, both the sustainability of the environment and the business itself are given equal priority in the selection of the EPM's. The quantified approach consequently can be seen to 'inform on degradation and depletion' of natural resources.

\section{$\underline{\text { Conclusion }}$}

Environmental issues have major implications on both a company's business sustainability as well as the obvious impacts on 'green sustainability'. In order for businesses to benefit from their recognition of this, a successful measurement and monitoring programme is needed. Environmental Performance measures can satisfy this demand provided they meet a number of criteria:

-EPM's should 'inform on degradation and depeltion';

-EPM's should reflect the companies environmental and other business concerns;

- they should satisfy the demands of shareholders, regulators and customers, and

- they should be quantifiable on a recognised scale.

\section{References:}

Bartelmus P. (1994) Environmental Growth and Development: the concepts and strategies of sustainablity, Routledge, London.

Department of the Environment, (1990) Pesticides: Code of Practice for the Safe use of Pesticides on Farms and Holdings. HMSO London, ISBN 0-11-242892-4.

Department of the Environment, (1993) Code of Practice for Agricultural use of Sewage Sludge, HMSO, London, ISBN 0-11-752256-2.

Gray R, Bebbington J. and Walters D. (1993) Accounting for the Environment, Paul Chapman Publishing Ltd, London.

James, P. and Bennett, M. (1994) Environment Related Performance Measurement in Business: from emissions to profit and sustainability, Ashridge Management Research Group, Ashridge.

Ministry of Agriculture, Fisheries and Food, Codes of Practice for the Protection of Water

(1992), Soil (1993) and Air (1991), Three individual publications, PB0587, PB0617 and PB0618 respectively, MAFF Publications, London.

Ministry of Agriculture, Fisheries and Food, (1994) Fertiliser Recommendation for Agricultural and Horticultural Crops (RB209), MAFF, London.

Pearce, D. (1993) Blueprint 3 Measuring Sustainable Developmen, Earthscan, London.

UN Environment and Development-UK (1994) An overview of the UN Environment and

Development-UK 1994 Round Table on Land, Sustainable Agriculture and

Rural Development: Chapter 14 and related sections of the United Nations

Summit Agenda 21, United Nations briefing paper.

WCED (1993) Our Common Future, Oxford University Press, Oxford and New York, Paul Chapman Publishing Ltd., London.

Welford, R.(1993) Breaking the link between quality and the environment: auditing for sustainability and life cycle assessment, Business Strategy and the Environment 2,(3). 
TABLE 1: DATA FROM FINANCIAL REPORTS AND ACCOUNTS FOR 'WATER ONLY COMPANIES' FROM 1989/90 TO 1994

\begin{tabular}{|c|c|c|c|c|c|}
\hline YEAR & $\begin{array}{l}\text { Average number } \\
\text { EPM's informing } \\
\text { degradation }\end{array}$ & $\begin{array}{c}\text { Average number } \\
\text { EPM's informing } \\
\text { depletion }\end{array}$ & $\begin{array}{c}\text { Average number } \\
\text { informing depletion } \\
\text { \& degradation }\end{array}$ & $\begin{array}{c}\text { Average number of } \\
\text { environmental } \\
\text { measures identified }\end{array}$ & $\begin{array}{c}\text { Average } \\
\text { score/measure } \\
\text { quality rating }\end{array}$ \\
\hline 1990 & 1.0 & 0.75 & 0.88 & 4.5 & 2.5 \\
\hline 1991 & 0.75 & 1.25 & 2.0 & 5.0 & 2.15 \\
\hline 1992 & 0.6 & 1.0 & 1.25 & 3.3 & 2.82 \\
\hline 1993 & 1.0 & 1.25 & 2.25 & 4.5 & 2.97 \\
\hline 1994 & 1.25 & 1.0 & 2.25 & 4.75 & 2.23 \\
\hline
\end{tabular}

TABLE 2: DATA FROM FINANCIAL REPORTS AND ACCOUNTS FOR WATER SERVICE PLC'S FROM 1989/90 TO 1994

\begin{tabular}{|c|c|c|c|c|c|}
\hline YEAR & $\begin{array}{c}\text { Average number } \\
\text { EPM's informing } \\
\text { degradation }\end{array}$ & $\begin{array}{c}\text { Average number } \\
\text { EPM's informing } \\
\text { depletion }\end{array}$ & $\begin{array}{c}\text { Average number } \\
\text { informing depletion \& } \\
\text { degradation }\end{array}$ & $\begin{array}{c}\text { Average number of } \\
\text { environmental } \\
\text { measures identified }\end{array}$ & $\begin{array}{c}\text { Average score/measure } \\
\text { quality rating }\end{array}$ \\
\hline 1990 & 3.0 & 1.25 & 4.25 & 7.0 & 1.72 \\
\hline 1991 & 3.75 & 1.25 & 5.0 & 8.0 & 1.73 \\
\hline 1992 & 2.75 & 1.75 & 4.5 & 9.75 & 1.73 \\
\hline 1993 & 3.0 & 1.25 & 4.25 & 9.0 & 2.18 \\
\hline 1994 & 2.75 & 1.25 & 4.0 & & 2.19 \\
\hline
\end{tabular}


TABLE 3: DATA FROM WATER INDUSTRY FINANCIAL REPORTS FOR 1994

\begin{tabular}{|c|c|c|c|}
\hline MEASURE & $\begin{array}{l}\text { WATER ONLY } \\
\text { COMPANIES }\end{array}$ & $\begin{array}{c}\text { WATER SERVICE } \\
\text { PLC'S }\end{array}$ & TOTAL \\
\hline Average no. of degradation measures. & 1.2 & 2.5 & 1.9 \\
\hline Average no. depletion measures. & 0.8 & 1.0 & 0.9 \\
\hline Degradation measures explained by regulator pressure & $100 \%$ & $100 \%$ & $100 \%$ \\
\hline Depletion measures explained by regulator pressure & $33 \%$ & $25 \%$ & $29 \%$ \\
\hline Average number of environmental measures. & 4.2 & 6.6 & 5.6 \\
\hline Average score per measure quality rating & 1.9 & 2.5 & 2.1 \\
\hline
\end{tabular}


TABLE 4: THE NUMBER OF EPM'S PER SUBJECT AREA AND THOSE DRIVEN BY REGULATORS IN THE WATER SERVICE PLC'S

ENVIRONMENTAL REPORTS.

\begin{tabular}{|c|c|c|c|}
\hline SUBJECT AREA & $\begin{array}{c}\text { TOTAL NUMBER OF } \\
\text { MEASURES }\end{array}$ & $\begin{array}{c}\text { TOTAL NUMBER OF } \\
\text { DEPRECIATION } \\
\text { MEASURES }\end{array}$ & $\begin{array}{c}\text { TOTAL NUMBER OF } \\
\text { DEGRADATION MEASURES }\end{array}$ \\
\hline Environmental management & $1(0)$ & $0(0)$ & $0(0)$ \\
\hline Legislation & $2(2)$ & $0(0)$ & $0(0)$ \\
\hline Surface \& groundwater quality (inland) & $10(10)$ & $1(1)$ & $2(2)$ \\
\hline Surface \& groundwater quality (coastal) & $6(5)$ & $0(0)$ & $1(1)$ \\
\hline Water quality & $4(3)$ & $0(0)$ & $0(1)$ \\
\hline Waste management & $8(3)$ & $2(0)$ & $3(3)$ \\
\hline Water resources & $13(8)$ & $6(4)$ & $0(0)$ \\
\hline Environmental health & $7(7)$ & $2(0)$ & $0(0)$ \\
\hline Energy & $3(0)$ & $1(0)$ & $0(0)$ \\
\hline Transport & $2(0)$ & $0(0)$ & $0(0)$ \\
\hline Conservation & $11(11)$ & $0(0)$ & $0(0)$ \\
\hline Environment \& community & $3(1)$ & $0(0)$ & $0(0)$ \\
\hline Sustainability & $0(0)$ & $0(0)$ & $0(0)$ \\
\hline Health \& safety & $0(0)$ & $0(0)$ & $4(3)$ \\
\hline Air & $3(2)$ & $0(0)$ & $0(0)$ \\
\hline Verification & $7(3)$ & $0(0)$ & $13(12)$ \\
\hline Total & $1(0)$ & $0(0)$ & \\
\hline
\end{tabular}

The numbers in brackets represent the number of EPM's which are influenced by regulatory control. 